\title{
AVALIAÇÃO DA QUALIDADE DAS SILAGENS DE GIRASSOL, MILHO, SORGO E MILHETO EM DIFERENTES ESPAÇAMENTOS
}

$\begin{array}{r}\text { AMIN, William Garofo }{ }^{1} \\ \text { MELLO, Sílvio de Paula }{ }^{2} \\ \hline\end{array}$

Recebido em: 2009-03-25

Aprovado em: 2009-04-29

Issue DOI: $10.3738 / 1982.2278 .183$

\begin{abstract}
RESUMO: O experimento foi realizado no Campus da FAFRAM, Faculdade "Dr. Francisco Maeda", no município de Ituverava - SP, com objetivo de avaliar a qualidade de silagem nas culturas de girassol, milho, milheto e sorgo em diferentes espaçamentos. O delineamento experimental foi o de blocos ao acaso, em um esquema fatorial 4 × 4 (4 culturas e 4 espaçamentos), totalizando 16 tratamentos com duas repetições. Cada parcela foi constituída por três metros lineares, espaçadas de $0,50,0,60,0,70$ e 0,80 metros. Os dados foram submetidos à análise de variância e comparação das médias pelo teste de Tukey, tendo estabelecido o nível de 5\% de probabilidade de erro. A análise bromatológica das silagens foi realizada para obter as porcentagens de matéria seca (MS), proteína bruta (PB) e nitrogênio. As análises foram realizadas pelo laboratório de bromatologia da Faculdade Dr. Francisco Maeda - FAFRAM. A cultura do sorgo apresentou 28,49 \% de matéria seca e a cultura do milheto apresentou 7,32\% de proteína bruta e 1,17\% de nitrogênio, sendo porcentagens significativas. Quanto aos espaçamentos de 0,50, 0,60, 0,70 e 0,80 m as médias de \% MS, \% PB e \% N não foram significativas. Concluiu-se que, a cultura que se destacou nas porcentagens de matéria seca foi o sorgo e nas porcentagens de proteína bruta foi a do milheto. Independentemente dos espaçamentos, as silagens apresentaram boas qualidades.
\end{abstract}

Palavras-chave: Silagens. Qualidade. Espaçamentos.

SUMMARY: The experiment was conducted on the campus of FAFRAM, Faculty "Dr. Francisco Maeda "in the municipality of Ituverava - SP, to evaluate the quality of silage on crops of sunflower, corn, millet and sorghum in different spacings. The experimental design was a randomized blocks in a factorial $4 \times 4$ (4 crop spacing and 4), totaling 16 treatments with two replications. Each plot was formed by three meters, spaced 0,50, 0,60, 0,70 and 0,80 meters. The data were submitted to variance analysis and comparison of means by Tukey test having set the level of 5\% probability of error. The chemical analysis of silage was carried out to obtain the percentage of dry matter (MS), crude protein (PB) and nitrogen. The tests were performed by the laboratory of Dr. Francisco School of Bromatology Maeda - FAFRAM. The cultivation of sorghum had 28,49\% of dry matter and growing millet showed $7,32 \%$ of crude protein and $1,17 \%$ nitrogen, with significant percentages. As for spacing of $0,50,0,60$, 0,70 and $0,80 \mathrm{~m}$ with averages of $\% \mathrm{MS}, \% \mathrm{~PB}$ and $\% \mathrm{~N}$ were not significant. It was concluded that the culture that stood out in the percentage of dry matter was the sorghum and the percentage of crude protein was that of millet. Regardless of spacing, the silage had good qualities.

Keywords: Silage. Quality. Spacings.

$1 \quad$ Acadêmico do curso de Agronomia da FE/FAFRAM

2 Professor Dr. em Genética e Evolução (UFSCar) - FE/FAFRAM - email: spmello@feituverava.com.br 


\section{INTRODUÇÃO}

Silagem é a forragem verde, suculenta, conservada por meio de um processo de fermentação anaeróbica, guardadas em silos. A ensilagem é o processo de cortar a forragem, colocá-la no silo, compactá-la e protegê-la com a vedação do silo para que haja a fermentação (CARDOSO; SILVA, 2007).

O valor nutritivo da silagem é semelhante ao da forragem verde, quando bem feita. A ensilagem não melhora a qualidade das forragens, apenas conserva a qualidade original (CARDOSO; SILVA, 2007).

A utilização de silagens tem sido uma eficiente solução para os períodos de baixa produção de forragens, proporcionando volumoso de boa qualidade e largamente utilizada na alimentação de ruminantes. A silagem de girassol apresenta composição bromatológica distinta à silagem de milho ou sorgo, com maior teor de proteína bruta e extrato etéreo (POSSENTTI, 2005).

As culturas de milho e sorgo têm sido as espécies mais utilizadas no processo de ensilagem, por sua facilidade de cultivo, altos rendimentos e especialmente pela qualidade da silagem produzida, sem necessidade de aditivo para estimular a fermentação (ZAGO, 2008).

O milho (Zea mays L.) é a espécie forrageira mais utilizada para esta finalidade, entretanto, outras culturas, por se adaptarem melhor as condições climáticas e de solo menos favoráveis, têm sido recomendadas, como o sorgo (Sorghum bicolor (L). Moench) e o girassol (Helianthus annus L.) (POSSENTI, 2005).

A cultura do sorgo para a ensilagem vem crescendo e representa grande percentual da área total cultivada para silagem no Brasil. Segundo os mesmos autores, as principais justificativas para a crescente expansão da cultura do sorgo no país foram altas produções por hectare; bom valor nutritivo ( $72 \%$ a $92 \%$ do valor nutricional da silagem de milho); tolerância a déficits hídricos ocasionais e possibilidade de rebrota.

Quanto ao potencial produtivo do milheto, pode alcançar até 60 toneladas de massa verde e 20 toneladas de matéria seca por hectare, quando cultivado no início da primavera (RIBEIRO, 2002).

Conforme Zago (2008), para se produzir uma silagem de alta qualidade é muito importante estar atento a algumas regras básicas, que se iniciam antes mesmo do plantio propriamente dito. E muitos desses cuidados não vão custar nada a mais para o produtor e poderão resultar numa silagem de melhor qualidade e menor custo, tais como: escolha da área e preparo do solo; correção e adubação do solo; definição do híbrido; operação de plantio; condução da lavoura; momento de corte da lavoura; amostragem para determinação do valor nutritivo da silagem; cuidados na ensilagem; retirada da silagem e fornecimento da silagem para os animais.

O objetivo do trabalho foi avaliar a qualidade de silagem nas culturas de girassol, milho, milheto e sorgo em diferentes espaçamentos.

Nucleus Animalium, v.1, n.1, maio 2009 


\section{REVISÃO DA LITERATURA}

Silagem é um método de conservação de forragem para alimentação de animais. Matéria orgânica proveniente da colheita de plantações comerciais, usualmente leguminosas ou gramíneas bem picadas, armazenada em silos verticais ou trincheiras revestidas com plástico, e bem tapadas para evitar o contacto com o ambiente. O material resultante passa por um processo de anaerobiose, isto é, na ausência de oxigênio, por acidificação do material verde vegetal e pode ser utilizado como alimento de gado ruminante nas épocas de ausência do alimento ao natural (WIKIPÉDIA, 2008).

A prática da confecção de silagem tem sido cada vez mais comum na produção de gado de corte, principalmente em regiões com exploração pecuária mais tecnificada, onde a procura por melhores índices zootécnicos e rentabilidade econômica tem levado grande número de produtores, que utilizam o confinamento, a adotarem sistematicamente essa prática. Outro fator que tem contribuído para o aumento da ensilagem é a integração agricultura-pecuária, entrando a lavoura como forma de reduzir o custo de recuperação ou renovação de pastagem (SILVA, 2001).

Segundo Silva (2001) uma boa silagem deve ter cheiro agradável e cor clara. Grandes quantidades de efluentes escorrendo indicam a possibilidade de fermentação inadequada. Uma silagem muito seca indica que pode ter havido problemas na compactação.

A presença de mofo é um indicativo da presença de ar oriundo da má compactação ou da vedação inadequada. $\mathrm{O}$ pH de uma boa silagem deve ser inferior a 4,2. A análise de ácidos orgânicos deve indicar valor acima de $2 \%$ de ácido lático e inferior a $0,1 \%$ de ácido butírico da matéria seca. A degradação de proteína é um sinal de fermentação indesejável e o nível de nitrogênio amoniacal de uma boa silagem deve ser inferior a $11 \%$ do nitrogênio total (SILVA, 2001).

No âmbito nacional, a cultura do milho pode ser considerada a mais importante, tanto sob o aspecto econômico quanto social. O milho é uma cultura muito utilizada para confecção de silagem no Brasil, por apresentar pronunciada expressão no rendimento de massa verde por unidade de área e excelente qualidade de fermentação e manutenção do valor nutritivo da massa ensilada, conferindo baixo custo operacional de produção, além da boa aceitabilidade por parte dos bovinos. O sucesso na produção de silagem, todavia, depende do grau de adaptação dos diferentes genótipos frente às características edafoclimáticas da área de cultivo (ALVES FILHO; RESTLE; BRONANI, 2000).

A silagem de milho é tida como padrão e, geralmente, considerada referência para comparação de valor com outras silagens (Henrique, Andrade; Sampaio, 1998). Contudo, sua produtividade e qualidade são incertas de ano para ano por serem influenciadas, dentre outros fatores, pela disponibilidade de água no solo (NUSSIO, 1991).

Para Bezerra; Tiesenhausen; Oliveira (1993) entre as forrageiras utilizadas como propósito de ensilagem, o milho é que mais se destacou, sobretudo em razão de seu valor 
nutritivo e de boa produção de massa por unidade de área plantada. Para esta prática, o milho (Zea mays, L.) é recomendado, tornando-se a espécie padrão, com valor nutritivo tomado como referência.

A quantidade de matéria seca produzida é uma das características mais importantes quando se objetiva a silagem. Koller; Mundstock (1972) observaram que o acúmulo de matéria seca nas partes vegetativas do milho cessa antes nos híbridos precoces que nos tardios, sendo que os híbridos precoces possuem uma translocação mais acentuada dos diversos órgãos da planta para a espiga.

Ferreira (1990 a), afirma que uma cultura de milho de porte medianamente alto, que produziria $4000 \mathrm{Kg} /$ ha produz para silagem, em torno de $9300 \mathrm{Kg}$ de matéria seca.

As cultivares de milho para silagem devem estar adaptadas à região de cultivo, objetivando bom desempenho na produção de matéria seca e com boa participação de grãos, resultando em alta produtividade de silagem de boa qualidade (SILVA, 1991).

Para a obtenção de silagem de boa qualidade, deve-se, contudo, utilizar materiais que possuam de 40 a 50\% de grãos na matéria seca do material ensilado (NUSSIO, 1992).

Costa (1997) cita que se deve dar preferência a cultivares que apresentem 40 a 50\% de grãos na matéria seca.

Em experimento realizado por Silveira et al (1979) em silagem de milho, foram obtidos valores de $31,8 \%$ de $\mathrm{MS}$ e $7,8 \%$ de PB.

Segundo Pereira et al (1993), as espigas de milho AG 405 representaram 34,6\% do total da matéria seca ensilada, e verificaram também 28,6\% de MS e 8,2\% de PB na MS.

Ferreira et al. (1991), verificaram em silagem de milho valores de 33,5\% de MS e $6,98 \%$ de PB.

Almeida Filho el al. (1999), verificaram valores de 33,99\% de MS e 8,12\% de PB em silagem de milho.

Os espaçamentos mais recomendados para silagem de milho ficam entre 70 e $90 \mathrm{~cm}$ entre linhas. Para cultivares de menor porte, pode-se usar espaçamento menor (entre 70 e 80 $\mathrm{cm}$ ) e para aquelas de maior porte ou mais tardias, deve-se adotar espaçamentos mais largos (90 cm) (MIRANDA; RESENDE; VALENTE, 2008).

O milheto é uma excelente alternativa para produção de silagem, principalmente em regiões com problemas de veranico ou seca. Presta-se ainda para plantio tardio ou de safrinha, após a colheita da cultura principal, para regiões nas quais não ocorrem geadas e que têm precipitações até o mês de maio. Nestas condições, o milheto pode alcançar produção superior ao sorgo, com melhor qualidade e também proporcionar boa cobertura do solo (KICHEL; MIRANDA, 2000).

Dentre as espécies estudadas, o milheto [Pennisetum glaucum (L.) R. Br.] é muito promissor por ser adaptado a vários tipos de solos, especialmente os arenosos, tolerante à baixa fertilidade do solo e às condições de déficit hídrico (BOGDAN, 1977). Essa gramínea proporciona alto rendimento, produzindo até próximo de $22 \mathrm{t}$ de $\mathrm{MS} / \mathrm{ha}$, conforme relatado por 
Andrade; Andrade (1982).

Apesar de apresentar ampla capacidade de adaptação, melhor conhecimento das características da planta de milheto é fator importante para a expansão e aproveitamento correto da cultura, pois seu comportamento pode variar em função das diferentes condições ambientais. A época de semeadura do milheto varia de região para região, podendo, em locais tropicais, ser semeado continuamente (ALCÂNTARA; BUFARAH, 1988).

Segundo Kichel; Miranda (2000) o milheto é uma forrageira de clima tropical, anual, de hábito ereto, porte alto, com desenvolvimento uniforme e bom perfilhamento, e produção de sementes entre $500 \mathrm{~kg} / \mathrm{ha}$ e $1.500 \mathrm{Kg} / \mathrm{ha}$. Apresenta excelente valor nutritivo (até $24 \%$ de proteína bruta quando em pastejo), boa palatabilidade e digestibilidade (60\% a 78\%) em pastejo, sendo atóxica aos animais em qualquer estádio vegetativo. Quanto ao potencial produtivo de forragem, pode alcançar até 60 toneladas de massa verde e 20 toneladas de matéria seca por hectare, quando cultivado no início da primavera.

Para uma eficiente germinação das sementes, é necessário que a temperatura média do solo seja superior a $20^{\circ} \mathrm{C}$, além de haver umidade suficiente para a emergência das plântulas. Por isso, o milheto pode ser semeado no início da primavera, por ocasião das primeiras chuvas, até início do outono: a semeadura poderá ser efetuada a lanço ou em linha, sendo que de preferência deve-se utilizar a semeadura em linha. Utilizam-se $18 \mathrm{~kg}$ a $20 \mathrm{~kg}$ de semente/ha, com espaçamento de $20 \mathrm{~cm}$ a $30 \mathrm{~cm}$ entre linhas para utilização em pastejo. Ou 12 a $15 \mathrm{~kg} / \mathrm{ha}$, com espaçamento entre linhas de $40 \mathrm{~cm}$ a $60 \mathrm{~cm}$ para produção de grãos, sementes ou silagem. A profundidade de semeadura pode variar de $2 \mathrm{~cm}$ a $4 \mathrm{~cm}$. Para semeadura a lanço utiliza-se $20 \%$ a mais de semente/ha. No caso de sobre semeadura em lavouras de soja, milho, sorgo, arroz etc., utiliza-se de $30 \mathrm{~kg}$ a $35 \mathrm{~kg}$ de sementes/ha (MILHETO, 2008).

O sorgo é uma cultura promissora, devido ao sistema radicular desenvolvido e outras características relacionadas à resistência à seca (Alvarenga, 1994), sendo favorecido seu cultivo na safrinha, com menores riscos do que na cultura do milho. Segundo Zago (1991), a tolerância à seca faz do sorgo uma das espécies preferidas para o cultivo na safrinha. Além disso, possui capacidade produtiva e valor nutritivo elevados e possibilidade de aproveitamento da rebrota, com produção de até $60 \%$ do primeiro corte.

A cultura do sorgo tem se destacado em razão da sua maior produtividade em condições adversas, principalmente de deficiência hídrica, baixa fertilidade do solo, amplitude na época de plantio e por mostrar maior tolerância a moléstias e pragas do que a cultura do milho (BOIN, 1985; DEMARCHI et al., 1995), além de possuir valor energético equivalente a 85 e 90\% do milho (VALENTE, 1992). Esta comparação, contudo, não pode ser aplicada indistintamente a todos os cultivares de sorgo, uma vez que existe grande variação entre sorgos (granífero, forrageiro e duplo propósito) quanto à produção de matéria seca e concentração de nutrientes.

As folhas de sorgo apresentam alta digestibilidade, mas seus grãos devido ao alto conteúdo de tanino apresentam baixa digestibilidade. Caules com uma alta proporção de parede celular são de baixa digestibilidade. Portanto, o valor nutritivo da silagem pode ser melhorado 
com a diminuição da proporção de caules na sua constituição. De maneira geral, as silagens de sorgo, têm sido reputadas como apresentando de 85 a 90\% do valor nutritivo da silagem de milho. Atualmente tem-se procurado desenvolver híbridos que tenham um bom equilíbrio entre colmo, folhas e panícula, objetivando-se obter boas produtividades com bom valor nutritivo (ZAGO, 1991).

O teor de matéria seca (MS) da planta é um fator determinante do tipo de fermentação no processo de ensilagem. Nos sorgos esse teor varia com a idade do corte e com a natureza do colmo da planta (Carvalho et al, 1992) geralmente híbridos de sorgo como colmo seco elevam o teor de matéria seca mais precocemente com a maturação (ZAGO, 1991).

Flaresso; Gross; Almeida (2000) verificaram que híbridos de sorgo mais tardios, como o AG-2002 com 128 dias, tenderam a apresentar maior altura $(3,43 \mathrm{~m})$ e maior rendimento (21.657 Kg/ha de MS) comparado ao híbridos mais precoces, como o AG-2005 E, com 133 dias, com menor altura $(1,94 \mathrm{~m})$ e menor rendimento $(14.691 \mathrm{Kg} / \mathrm{ha}$ de MS).

O girassol é uma planta originária do continente norte americano, pertencente à família das Compostas, possui raiz pivotante profunda, que atinge cerca de 2 metros ou mais de profundidade, ciclo vegetativo médio de 120 a 130 dias e efeito alelopático sobre algumas ervas daninhas, reduzindo a utilização de herbicidas, além de poder ser utilizado como adubação verde (ROSSI, 1998). Na literatura são encontrados estudos sobre o aproveitamento da planta de girassol na dieta de ruminantes, utilizando-se os receptáculos (MADAN MOHAN et al., 1997), cascas dos grãos (MARX, 1977), planta inteira como forragem verde (LLOVERAS, 1990) ou ensilada (HENRIQUE, ANDRADE; SAMPAIO, 1998; SILVA et al., 1998).

As vantagens no emprego do girassol na ensilagem em comparação ao milho e sorgo têm sido atribuída a sua maior produção de massa verde por área (GONÇALVES et al., 1996); maior resistência à seca, devido a sua alta capacidade de extrair água do solo, estimada em, aproximadamente, 92\% contra 64\% do sorgo (BREMMER; PRESTON; GROTH, 1986); resistência ao frio e geadas, devido à ampla adaptabilidade as diferentes condições edafoclimáticas (SOUZA, 1998); a seu menor período vegetativo e alta qualidade do produto final ensilado, especialmente pelo maior conteúdo de proteína possibilitando economia no balanceamento de rações (TOMICH, 1999).

No Brasil, o girassol (Helianthus annuus, L.) tem sido objeto de muitas pesquisas na área da fisiologia vegetal, em razão do elevado potencial fotossintético, das altas taxas de crescimento, da capacidade em extrair e conduzir a água e dos movimentos diaeliotrópicos das folhas e do capítulo, porém, poucos estudos são feitos envolvendo a produção de girassol para ensilagem (CASTRO; CASTIGLIONI; BALLA, 1993).

Avaliando a qualidade das silagens de treze cultivares de girassol TOMICH (1999) classificou-as como de muito boa qualidade quanto aos teores de nitrogênio amoniacal, boa qualidade quanto aos teores de MS e como de média qualidade em relação aos valores de $\mathrm{pH}$. No entanto, PEREIRA et al. (1999), estudando a fermentação de seis genótipos de girassol relataram que os teores de MS decaíram com o decorrer do processo fermentativo, os valores 
de $\mathrm{pH}$ estabilizaram-se após 14 dias de vedação dos silos e a proteólise provocou mudanças significativas nos teores de PB ao longo da fermentação, não sendo observada a estabilização da proteólise durante os períodos de abertura dos silos, em alguns genótipos estudados.

Para Gonçalves; Costa (2008) o espaçamento ideal varia de 80 a 90 centímetros entre linhas, variando a população ideal de 40.000 a 45.000 plantas por hectare (4 plantas por metro) no final do ciclo, conforme o híbrido ou cultivar. O consumo médio de sementes varia de 3,5 a 4,0 quilos por hectare.

\section{MATERIAL E MÉTODOS}

O trabalho experimental foi conduzido no Campus da FAFRAM, Faculdade "Dr. Francisco Maeda", localizada no município de Ituverava, SP, situada a $20^{\circ} 20^{\prime} 30^{\prime \prime}$ de latitude $\mathrm{S}$ e $47^{\circ} 47^{\prime} 30^{\prime \prime}$ de longitude W e altitude de 631 metros, no período de novembro de 2007 a fevereiro de 2008.

Foi realizado o manejo de plantio convencional. O solo foi preparado através de uma aração com grade aradora, seguida de uma gradagem leve com a finalidade de eliminar os torrões e uniformizar o terreno e, os sulcos foram abertos com a enxada.

O plantio do milho, milheto, sorgo e girassol foram realizados manualmente no dia $14 / 11 / 2007$, submetidos a diferentes espaçamentos de 0,$5 ; 0,6 ; 0,7$ e $0,8 \mathrm{~m}$ e uma distribuição de sementes visando $60 \mathrm{mil} \mathrm{plantas/ha,} \mathrm{nas} \mathrm{culturas} \mathrm{do} \mathrm{milho} \mathrm{e} \mathrm{girassol} \mathrm{e} 120 \mathrm{mil} \mathrm{plantas} / \mathrm{ha}$ de milheto e sorgo.

A silagem foi feitas através de uma picadora movida pela TDP do trator específica para silagens e foi armazenada em mini-silos de tubos de PVC de $150 \mathrm{~mm}$ de diâmetro e $80 \mathrm{~cm}$ de altura, sendo enterrados no solo, sob a sombra das árvores existentes no local.

Após o enchimento, os silos foram fechados com lona, sendo mantidos assim durante 60 dias até a retirada das amostras. Para retirar as amostras desprezaram-se os primeiros $20 \mathrm{~cm}$ de silagem, retirando a parte central do mini-silos.

O delineamento experimental foi o de blocos ao acaso, em um esquema fatorial 4 x 4 (4 culturas e 4 espaçamentos), totalizando 16 tratamentos com duas repetições. Cada parcela foi constituída por três metros lineares, espaçadas de $0,50,0,60,0,70$ e 0,80 metros.

Os dados foram submetidos à análise de variância e comparação das médias pelo teste de Tukey, tendo estabelecido o nível de 5\% de probabilidade de erro.

\section{RESULTADOS E DISCUSSÃO}

A Tabela 2 apresenta os valores das porcentagens obtidas de Matéria Seca (MS), Proteína Bruta (PB) e Nitrogênio (N) de acordo com as culturas de milho, sorgo, milheto e girassol e espaçamentos.

Nucleus Animalium, v.1, n.1, maio 2009 
TABELA 2 - Porcentagens obtidas de Matéria Seca (\%MS), Proteína Bruta (\%PB) e Nitrogênio $(\% \mathrm{~N})$ em relação a diferentes culturas e espaçamentos.

\begin{tabular}{|c|c|c|c|}
\hline 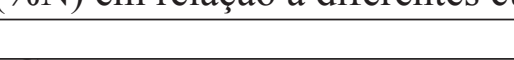 & $\% \mathrm{MS}$ & $\%$ PB & $\% \mathrm{~N}$ \\
\hline \multicolumn{4}{|l|}{ Culturas } \\
\hline Milho & $26,07 \mathrm{~b}$ & $5,74 \mathrm{~b}$ & $0,92 \mathrm{~b}$ \\
\hline Sorgo & $28,49 \mathrm{a}$ & $6,43 \mathrm{ab}$ & $1,03 \mathrm{ab}$ \\
\hline Milheto & $24,87 \mathrm{~b}$ & $7,32 \mathrm{a}$ & $1,17 \mathrm{a}$ \\
\hline Girassol & $17,02 \mathrm{c}$ & $6,54 \mathrm{ab}$ & $1,04 \mathrm{ab}$ \\
\hline \multicolumn{4}{|l|}{ Espaçamento } \\
\hline 0,50 & $23,47 \mathrm{a}$ & $6,77 \mathrm{a}$ & $1,02 \mathrm{a}$ \\
\hline 0,60 & $24,62 \mathrm{a}$ & $6,49 \mathrm{a}$ & $1,04 \mathrm{a}$ \\
\hline 0,70 & $23,86 \mathrm{a}$ & $6,22 \mathrm{a}$ & $0,99 \mathrm{a}$ \\
\hline 0,80 & $24,50 \mathrm{a}$ & $6,96 \mathrm{a}$ & $1,11 \mathrm{a}$ \\
\hline Coeficiente de Variacão (\%) & 4,81 & 14.83 & 14.84 \\
\hline Média Geral (\%) & 24,11 & 6,51 & 1,04 \\
\hline
\end{tabular}

Médias seguidas da mesma letra, na coluna não diferem estatisticamente entre si (Teste Tukey 5\%).

A cultura do sorgo apresentou $28,49 \%$ diferindo das demais quanto à matéria seca, a cultura do milheto apresentou 7,32 \% de proteína bruta e 1,17\% de nitrogênio, igual estatisticamente à cultura do sorgo e do girassol, sendo porcentagens significativas.

Quanto aos espaçamentos de 0,50, 0,60, 0,70 e 0,80 $\mathrm{m}$ as médias de \% MS, \% PB e \% $\mathrm{N}$ não foram significativas.

Keplin (1996) sugeriu valores básicos de proteína bruta para avaliação nutritiva da silagem de milho com as seguintes classificações: menor que 5\%, muito fraco; $5-6 \%$, fraco; $6,1-7 \%$, bom; acima de $8 \%$, muito bom. O presente trabalho, quanto aos valores básicos de proteína bruta segundo Keplin, a cultura do milho classificou-se como fraco, uma vez que apresentou resultado de $5,74 \%$.

Lavezo et al (1997) analisaram a composição bromatológica da silagem do milho e obtiveram para a MS valores de $29,82 \%$ e PB de 7,23\%, também superiores aos obtidos neste trabalho.

Franco Júnior (1997) obteve 23,57\% a 27,52\% de matéria seca e $7,09 \%$ a $8,40 \%$ de proteína bruta para a cultura do milho, resultado igual quanto à matéria seca e superior ao de proteína bruta conforme o presente trabalho.

Dias (2000) em experimento avaliando dez híbridos de milho através de análises quantitativas e qualitativas de suas silagens, obteve valores de MS (matéria seca) de 28,67\% a $33,75 \%$ e PB (proteína bruta) de $6,17 \%$ a $7,96 \%$, valores superiores aos obtidos no presente trabalho.

Em trabalho realizado por Nakaghi (2006) com o objetivo de avaliar a produtividade e a qualidade da silagem de híbridos de milho, o valor obtido de proteína bruta no híbrido AG 5020 foi de $8,17 \%$ e no híbrido AG 8060 de 6,19\%, valores que se encontram dentro da média, entre 6 a 9\% segundo Dourado Neto; Francelli (2000), diferentemente do obtido no presente trabalho.

Bettarello (2000) em experimento avaliando quantitativamente e qualitativamente a 
produção de sorgo para silagem, sob diferentes doses de adubação nitrogenadas obteve valores médios de matéria seca de 26,9 a 30,1\% valor semelhante ao presente trabalho. E quanto ao valor médio de proteína bruta entre 6,9 a 7,8\%, superior ao encontrado neste trabalho.

\section{CONCLUSÃO}

Concluiu-se que, a cultura que se destacou nas porcentagens de matéria seca foi o sorgo e nas porcentagens de proteína bruta não houve diferença significativa entre as culturas do milheto, sorgo e girassol. Independentemente dos espaçamentos, as silagens apresentaram boas qualidades.

\section{REFERÊNCIAS}

ALCÂNTARA, P. B.; BUFARAH, G. Plantas forrageiras: gramíneas e leguminosas. 4 ed. São Paulo: Nobel, 1988. 162p.

ALMEIDA FILHO, et al. Características agronômicas de cultivares de milho (Zea mays L.) e qualidade dos componentes da silagem. Revista Brasileira de Zootecnia, v.28, n.1, p.7-13, 1999.

ALVES FILHO, D.C.; RESTLE, J.; BRONANI, I.L. et al. Silagem de sorgo ou milho para terminação de novilhos em confinamento. In: REUNIÃO ANUAL DA SOCIEDADE BRASILEIRA DE ZOOTECNIA, 37., 2000, Viçosa, MG. Anais... Viçosa: SBZ, 2000. CDROM.

ANDRADE, J.B.; ANDRADE, P. Produção de silagem do milheto (Pennisetum americanum (L.) K. Schum.). Boletim de Indústria Animal, Nova Odessa, v.39, n.2, p.155-165, jul./dez. 1982.

BETTARELlO, C. B. P. Avaliação da produção e qualidade de silagem de sorgo (Sorghum bicolor) sob diferentes adubações nitrogenadas, 2000. 26p. Trabalho (Graduação em Engenharia Agrônomica). Faculdade "Dr. Francisco Maeda". Fundação Educacional de Ituverava.

BEZERRA, E.S., TIESENHAUSEN, I.M.E.V.V., OLIVEIRA, A.I.G. et al. 1993. Valor nutricional das silagens de milho, milho associado com sorgo e rebrotas de sorgo. R. Soc. Bras. Zootec., 22(6):1044-1054. 
BODGAN, A.V. Tropical pasture and fodder plants: grasses and legumes. London: Longman, 1977. 475p.

BOIN,C. Utilização de volumoso para gado de corte. In: SIMPÓSIO DE GADO DE CORTE, 1., 1985, São Paulo, Anais... São Paulo: v.1., p. 38-61, 1985.

BORGES, I. et al. Qualidade das silagens de três cultivares de milheto (CMS 01, CMS 02 E BN 02). 2002. a. Disponível em:< http://www.vet.ufmg.br/academicos/pesquisa-napq/encontro-depesquisa/resumos-de-2002-1/qualidade-das-silagens-de-tres-cultivares-de-milheto-cms-01cms-02-e-bn-02>. Acesso em: 26 de out. de 2008.

BORGES, I. et al. Padrão de fermentação das silagens de seis genótipos de girassol (CONTIFLOR 3, V200, M 742, AS 243, AS 603 E M 737). 2002. b. Disponível em:< http://www.vet.ufmg.br/ academicos/pesquisa-napq/encontro-de-pesquisa/resumos-de-2002-1/padrao-de-fermentacaodas-silagens-de-seis-genotipos-de-girassol-contiflor-3-v200-m-742-as-243-as-603-e-m-737>. Acesso em: 26 de out. de 2008.

BREMMER, P. M.; PRESTON, G. K.; GROTH, C. F. A field comparison of sunflower (Helianthus annus) and Sorghum (Sorghum bicolor) in along drying cycle. I. Water extration. Australian Journal of Agricultural Research, Cairo, v.37, n.5, p.483-493, 1986.

CARDOSO, E. G.; SILVA, J. M. da. O que é silagem? 2007. Embrapa Gado de Corte. Disponível em: < http://www.agroredenoticias.com.br/textos.aspx?htUpTLaCxzs//NiXdoozAg >. Acesso em: 15 de ago. de 2008.

CARVALHO, D. D. et al. Estádio de maturação na produção e qualidade da silagem de sorgo. I. Produção de MS e PB. Bol, Ind. Anim, v.49, p.91-99, 1992.

CASTRO, C.; CASTIGLIONI, V. B. R.; BALLA, A. et al. A cultura do girassol. Londrina: Embrapa-CNPSo, 1997. 36p. (Circular Técnica, 13)

COSTA, R. S. Avaliação dos caracteres agronômicas e químicas de doze cultivares de milho para ensilagem. Jaboticabal, 1997, p.97. (Trabalho apresentado a Faculdade de Ciências Agrárias e Veterinárias, UNESP, Campus de Jaboticabal, para graduação em Zootecnia).

DEMARCHI, J.J.A.A.; BOIN, C.; BRAUN, G. A cultura do sorgo (Sorghum bicolor L. Moench) para produção de silagens de alta qualidade. Zootecnia, Nova Odessa, v.33, n.3, p.111-136, jul/ set., 1995

Nucleus Animalium, v.1, n.1, maio 2009 
DIAS, A. R. Avaliação quantitativa e qualitativa de híbridos de milho (Zea mays L.) para silagem, 2000. 40p. Trabalho (Graduação em Engenharia Agrônomica). Faculdade "Dr. Francisco Maeda”. Fundação Educacional de Ituverava.

FERREIRA, J. J. Importância da racionalização da ensilagem no custo de produção da silagem de milho. Informe Agropecuário. Belo Horizonte, MG. v.14, n.164, p.50-52. 1990a.

FERREIRA, J. J. Aspectos importantes para melhor qualidade da silagem de milho e maior eficiência na sua utilização. Circular Técnica EMBRAPA. Milho para silagem: tecnologias, sistemas e custos de produção, n.14, p.59-67, 1991.

FLARESSO, J. A.; GROSS, C. D.; ALMEIDA, E. D. Cultivares de milho (Zea mays L.). e sorgo (Sorghum bicolor (L.) Moench) para ensilagem no Vale do Itajaí, Santa Catarina. Revista Brasileira de Zootecnia, v.29, n.6, p.1608-1615, 2000.

FRANCO JÚNIOR, S. M. Avaliação da produtividade e qualidade de híbridos de milho (Zea mays L.) para produção de silagem, 1997. 24p. Trabalho (Graduação em Engenharia Agrônomica). Faculdade "Dr. Francisco Maeda”. Fundação Educacional de Ituverava Ituverava.

GONÇALVES, L. C. et al. Produtividade e teor de matéria seca de girassol (Helianthus annuus) cultivados em diferentes épocas do ano e colhido em diferentes estágios vegetativos. In: REUNIÃO ANUAL DA SOCIEDADE BRASILEIRA DE ZOOTECNIA, 33., 1996, Fortaleza. Anais... Fortaleza: SBZ, v.33, 1996.

GONÇALVES, A. DE C.; COSTA, P. J. A. Silagem de girassol. Disponível em: $<$ http://www. projepec.com.br/Silagem\%20de\%20girassol.pdf > . Acesso em: 26 de out. de 2008.

HENRIQUE, W.; ANDRADE, J. B.; SAMPAIO. A. A. M. Silagem de milho, sorgo, girassol e suas consorciações. II. Composição bromatológica. In: REUNIÃO ANUAL DA SOCIEDADE BRASILEIRA DE ZOTECNIA, 35., 1998, Botucatu. Anais... Botucatu: SBZ, 1998. p.379381.

KEPLIN, L. A. S. Silagem de milho: fatores que definem qualidade e produção. Balde Branco, v.32, n.379, p.30-35, 1996.

KICHEL, A. N.; MIRANDA, C. H. B. Uso do milheto como planta forrageira. Embrapa Gado de Corte. Campo Grande, MS, dez. 2000 n. 46. 
KOLLER, O. L. ; MUNDSTOCK, C. M. . Distribuição da matéria seca na planta durante o período de formação dos grãos em seis cultivares de milho. In: IX REUNIAO BRASILEIRA DO MILHO, 1972, Recife, PE. Anais da IX Reunião Brasileira do Milho. Recife: Ministério da Agricultura, 1972. p. 150-158.

LAVEZZO, W. et al. Estádio de desenvolvimento do milho. 1. Efeito sobre a produção, composição da planta e qualidade de silagem. Revista de Zootecnia, v.26, n.4, Viçosa-MG. p.675-682, 1997.

LLOVERAS, J. Dry matter yield and nutritive value of four summer annual crops in northwoes Spain (Galicia). Grass and Forage Science, v.45, n.3, p.243-248, 1990.

MADAN MOHAN, A.; REDDY, G.V.N.; REDDY, M.R. Nutritive value and rumen fermentation pattern or sunflower (Helianthus annuus) heads in crossbred bulls. Indian Journal of Animal Nutrition, v.14, n.1, p.50-53, 1997.

MARX, G.D. Utilization of sunflower silage, sunflower hulls with poultry litter and sunflower hulls mixed with corn silage for growing dairy animals. Journal of Dairy Science, v.60, suppl. 1, p.112, 1977.

MILHETO. Semeadura. Disponível em: $<$ http://www.maxiagro-rs.com.br/index. php?id=2,9,0,0,1,0> . Acesso em: 26 de out. de 2008 .

MIRANDA; J. E. C. de.; RESENDE, H.; VALENTE, J. de O. Silagem de milho. Juiz de Fora, julho de 2008. Disponível em: $<$ http://www.cnpgl.embrapa.br/nova/sala/artigos/artigolinha. php?id=40>. Acesso em: 26 de out. de 2008.

NUSSIO, L. G. Cultura de milho para produção de silagem de alto valor alimentício. In: SIMPÓSIO SOBRE NUTRIÇÃO DE BOVINOS, 4., 1991, Piracicaba. Anais... Piracicaba: FEALQ, 1991.p.59-168.

NUSSIO, L. G. Produção de silagem de alta qualidade. In: CONGRESSO NACIONAL DE MILHO E SORGO, 19., 1992, Porto Alegre. Conferências... Porto Alegre: SAA/SCT/ABMS/ Emater-RS/Embrapa-CNPMS, 1992. p. 155-175.

PEREIRA, L.G.R. et al. Padrão de fermentação das silagens de seis genótipos de girassol (Helianthus annuus 1.). In: REUNIÃO ANUAL DA SOCIEDADE BRASILEIRA DE ZOOTECNIA, 36., 1999, Porto Alegre. Anais... Porto Alegre: SBZ, 1999. CD-ROM.

Nucleus Animalium, v.1, n.1, maio 2009 
PEREIRA, O. G. Produtividade de uma variedade de milho (Zea mays L.) e de três variedades de sorgo (Sorghum bicolor (L.) Moench) e o valor nutritivo de suas silagens. Revista da Sociedade Brasileira de Zootecnia, v.22, p.31-38, 1993.

POSSENTI, R. A. Parâmetros bromatológicos e fermentativos das silagens de milho e girassol. Ciência Rural, Santa Maria, v.35, n.5, p.1185-1189, 2005.

RIBEIRO, E. L. de A. et al. Silagens de girassol (Helianthus annus L.), milho (Zea mays L.) e sorgo (Sorghum bicolor (L.) Moench) para ovelhas em confinamento. Ciência Rural, Santa Maria, v.32, n.2, p.299-302, 2002.

ROSSI, R.O. Girassol. Curitiba: Tecnoagro, 1998, 333p.

NAKAGHI, M. S. Avaliação quantitativa e qualitativa da silagem de híbridos de milho (Zea mays L.) sem espigas, 29p. Trabalho de conclusão de curso (Graduação em Engenharia Agronômica). Faculdade Dr. Francisco Maeda. Fundação Educacional de Ituverava.

SILVA, J. M. da. Silagem de forrageiras tropicais. Embrapa Gado de Corte. Campo Grande, MS, 2001 n. 51. Disponível em: <http://www.cnpgc.embrapa.br/publicacoes/divulga/GCD51. html>. Acesso em: 26 de out. de 2008.

SILVA, A. F. Manejo cultural do milho forrageiro. In: Embrapa. Centro Nacional de Pesquisa de Milho e Sorgo (Sete Lagoas, MG). Milho para silagem: tecnologias, sistemas e custos de produção. Sete Lagoas, 1991, 85p. (Circular Técnica, 14).

SILVEIRA, A. C. et al. Estudo comparativo entre o valor nutritivo da silagem e do pé de milho seco e triturado. Revista da Sociedade Brasileira de Zootecnia, v.8, p.11-12, 1996.

SOUZA, D.B. Girassol: uma nova opção para silagem. Gado Holandês, n.472, p. 6-10, abr. 1998.

TOMICH, T. R. Avaliação do potencial forrageiro e das silagens de treze cultivares de girassol (Helianthus annuus L.). Belo Horizonte, 1999, 117p. Dissertação (Mestrado em Zootecnia) - Escola de Veterinária, Universidade Federal de Minas Gerais.

VALENTE, J. O. Introdução. In: MANEJO CULTURAL DO SORGO PARA FORRAGEM. Circular técnica, Embrapa-CNPMS, Sete Lagoas, MG, n.17, p.5-7. 1992. 
WIKIPÉDIA. A enciclopédia livre. Silagem. Disponível em: $<$ http://pt.wikipedia.org/wiki/ Silagem>. Acesso em 26 de out. de 2008.

ZAGO, C. P. Cultura do sorgo para produção de silagem de alto valor nutritivo. In: SIMPÓSIO SOBRE NUTRIÇÃO DE BOVINOS, 4., 1991, Piracicaba. Anais... Piracicaba: FEALQ, 1991. p. 169-218.

ZAGO, C. P. Silagem de milho e sorgo. 2008. Disponível em: $<$ http://www.biomatrix.com. $\mathrm{br} / \mathrm{br} /$ resources/download.php? file=../upload/arq_artigo/Artigo $\% 20$ Silagem $\% 20 \mathrm{de} \% 20$ milho\%20e\%20sorgo.pdf.>. Acesso em: 12 de ago. de 2008. 